\title{
Produção compartilhada de jogo educativo sobre álcool com adolescentes de comunidade Quilombola*
}

\section{Shared production of an educational game about alcohol with adolescents from the Quilombola Community}

\section{Producción compartida de un juego educativo acerca del alcohol con adolescentes de una comunidad Quilombola}

Recebido: $15 / 05 / 2020$

Aprovado: 15/07/2020

Publicado: 11/08/2020

\section{Adriana Nunes Moraes-Partelli ${ }^{1}$ Aline Pestana Santos ${ }^{2}$ Séfora Gasparini Santos ${ }^{3}$ Marta Pereira Coelho ${ }^{4}$}

Este estudo tem como objetivo descrever a experiência vivenciada na produção compartilhada de jogo educativo sobre álcool, tendo a participação de adolescentes de comunidade Quilombola. Trata-se de um relato de experiência desenvolvida no primeiro semestre de 2019, dividido nas etapas: atividade de campo com grupos adolescentes, utilizando o método criativo sensível, através de dinâmicas de criatividade e sensibilidade; construção de storyboard provisório pelos pesquisadores; e avaliação dos jogos e alterações do storyboard. Após aplicação das dinâmicas produziu-se storyboard provisório do jogo de imagens. Esse jogo foi avaliado pelos adolescentes e alterações foram realizadas, chegando-se a um material educativo produzido por eles e para eles que pode ser uma ferramenta transformadora do cuidado à saúde. Com as atividades realizadas foi possível uma aproximação mais efetiva com os adolescentes, sendo possível conhecer seus costumes, sua cultura e apreender como o álcool está presente no cotidiano dos moradores da comunidade.

Descritores: Materiais educativos e de divulgação; Adolescente; Educação em saúde; Grupo com ancestrais do Continente Africano.

This study aims to describe the experience lived in the shared production of an educational game about alcohol, with participation of adolescents from the Quilombola community. This is an experience report developed in the first semester of 2019, divided into stages: field activity with adolescent groups, using the sensitive creative method, through dynamics of creativity and sensitivity; construction of provisional storyboard by researchers; and game evaluation and storyboard changes. After applying the dynamics, a provisional storyboard of the image game was produced. This game was evaluated by teenagers and changes were made to educational material produced by them and for them that can be a transforming tool of health care. With activities carried out, it was possible to approach the teenagers more effectively, making it possible to know their customs, their culture and learn how alcohol is present in the daily lives of the community's residents.

Descriptors: Educational and promotional materials; Adolescent; Health education; African Continental ancestry group.

Este estudio tiene por objeto describir la experiencia vivida en la producción compartida de un juego educativo acerca del alcohol, con la participación de adolescentes de una comunidad Quilombola. Se trata de un informe de una experiencia desarrollada en el primer semestre de 2019, dividido en las etapas: actividad de campo con grupos de adolescentes, utilizando el método creativo sensible, mediante dinámicas de creatividad y sensibilidad; construcción de un storyboard provisional por parte de los investigadores; y evaluación de juegos y cambios del storyboard. Después de aplicar las dinámicas, se produjo el storyboard provisional del juego de imágenes. Este juego fue evaluado por los adolescentes y se hicieron cambios, obteniendo un material educativo producido por ellos y para ellos que puede ser una herramienta transformadora para el cuidado de la salud. Las actividades realizadas permitieron acercarse a los adolescentes y conocer sus costumbres, cultura, y aprender como el alcohol está presente en la vida cotidiana de los habitantes de la comunidad.

Descriptores: Materiales educativos y de divulgación; Adolescente; Educación en salud; Grupo de ascendencia Continental Africana.

* Estudo com financiamento da Fundação de Amparo à Pesquisa e Inovação do Espírito Santo (FAPES - 172/17)

1. Enfermeira. Especialista em Enfermagem Neonatal. Mestre em Ciências Fisiológicas. Doutora em Enfermagem. Professora do Curso de Graduação de Enfermagem

da Universidade Federal do Espírito Santo (UFES). São Mateus, ES, Brasil. ORCID: 0000-0001-9978-2994 E-mail: adrianamoraes@hotmail.com

2. Acadêmica do Curso de Graduação em Enfermagem da UFES. São Mateus, ES, Brasil. ORCID: 0000-0003-4463-0832 E-mail: alinepesttana@gmail.com

3. Acadêmica do Curso de Graduação em Enfermagem da UFES. São Mateus, ES, Brasil. ORCID: 0000-0002-2368-6194 E-mail: sefora-g-santos@hotmail.com

4. Enfermeira. Especialista em Saúde Pública. Especialista em Saúde do Idoso e Gerontologia. Mestre e Doutora em Enfermagem. Professora do Curso de Graduação

em Enfermagem da UFES. São Mateus, ES, Brasil. ORCID: 0000-0002-2046-6954 E-mail: martapereiracoelho@hotmail.com 


\section{INTRODUÇÃO}

$\mathbf{0}$ abuso ou uso nocivo do álcool é um fator preocupante em jovens e adolescentes, o consumo dessa substância expõe a saúde, podendo envolver complicações físicas ou psíquicas.

Dados de uma pesquisa nacional evidenciam que 55,5\% dos estudantes do 9 o ano do ensino fundamental, com idade de 13 a 15 anos, já relataram terem experimentado alguma bebida alcoólica, 21,4\% já sofreram algum episódio de embriaguez na vida, 7,3\% tiveram problemas com família ou amigos, faltaram aulas ou já se envolveram em brigas porque haviam ingerido bebida alcoólica ${ }^{1}$. Ademais, há relação da raça negra/parda com o consumo abusivo de álcool².

Compreendendo que a adolescência, segundo aspectos culturais e sociais estabelecidos em sociedade ${ }^{3}$, é um período em que o indivíduo está passando por uma fase de desenvolvimento para a formação de um cidadão adulto, a educação em saúde de forma dialógica, emancipadora, participativa e criativa estimula a autonomia do adolescente, no que diz respeito à sua condição de pessoa de direito e autor de sua trajetória de saúde e doença 4 .

As publicações existentes não contemplam a produção de jogo educativo sobre a temática do uso de álcool por adolescentes, muito menos para adolescentes negros Quilombolas. Este é um debate pautado entre os significados, conhecimentos e na valorização de experiências entre enfermeiros e adolescentes, utilizando uma abordagem pedagógica participativa e dialógica fundamentada em Paulo Freire ${ }^{5}$, com vistas, a construir propostas, fundada na promoção da saúde, adequadas à realidade do grupo.

No final de 2016, com a produção e avaliação, entre os pares, do almanaque "Álcool e ritos de adolescentes em uma comunidade Quilombola" esses obstáculos começaram a ser derrubados, tratando-se de uma tecnologia em saúde com produção compartilhada, unindo o conhecimento popular de adolescentes residentes em Comunidade Quilombola e o conhecimento científico sobre a temática álcool. 0 almanaque contém: histórias em quadrinhos (HQ), curiosidades, "você sabia" e passatempo. Porém, é indispensável o avanço em estudos que abordam a temática álcool na adolescência6.

Portanto, dar voz aos adolescentes residentes em comunidade Quilombola, construindo com eles(as) e para eles(as), um material educativo dialógico e interativo pode ser uma estratégia para a promoção do cuidado protetor da vida. Os materiais educativos existentes não alcançam esse grupo populacional específico, que se encontram à margem do acesso de informações sobre saúde.

A análise de materiais educativos, disponíveis na internet para os adolescentes, permitiu observar que os materiais têm como temática central os temas que afetam a saúde pública brasileira, e ainda não chamou atenção a problemática do álcool particularmente com os adolescentes Quilombolas, sendo esse almanaque o primeiro material educativo produzido que vai ao encontro dessa problemática. Há necessidade de avançar na produção de materiais educativos como o jogo.

Este relato tem como objetivo descrever a experiência vivenciada na produção compartilhada de jogo educativo sobre álcool, tendo a participação de adolescentes de comunidade Quilombola.

\section{MÉTODO}

Trata-se de um relato de experiência com adolescentes residentes em comunidade Quilombola que transformaram a história em quadrinhos (HQ) do almanaque "Álcool e ritos de adolescentes em uma comunidade Quilombola" em jogo educativo.

As atividades ocorreram no primeiro semestre de 2019 em uma comunidade Quilombola, semi-isolada, localizada em zona rural, a 44 quilômetros do município de São Mateus, Espírito Santo. A comunidade desempenha a agricultura familiar com o cultivo e 
comercialização de café conilon, pimenta do reino e frutas (coco, jaca, banana, manga, abacate, dentre outras). Carecem de garantia aos direitos básicos como educação de qualidade e saúde.

Participaram da produção do jogo educativo, adolescentes que atenderam aos critérios de inclusão: cursar o Ensino Fundamental e/ou Médio em escola pública localizada na zona rural; residir na comunidade Quilombola; ter idade entre 10 e 19 anos completos, que segundo a Organização Mundial de Saúde, é faixa etária entendida como adolescência; e ter habilidade cognitiva e motora preservadas. Foram excluídos adolescentes com doenças agudas e condições crônicas, fora do sistema de escolarização na área rural e que residissem fora da comunidade.

A participação foi voluntária e ocorreu após aceite dos pais ou responsáveis através da assinatura do Termo de Consentimento Livre e Esclarecido (TCLE) e assinatura pelos adolescentes do Termo de Assentimento (TA).

Para transformar HQ em jogo educativo, aplicou-se o Método Criativo Sensível (MCS) de pesquisa grupal baseada em arte ${ }^{7}$, com as Dinâmicas de Criatividade e Sensibilidade (DCS), nos seguintes encontros:

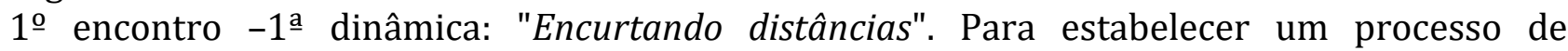
conhecimento e aproximação entre os participantes da pesquisa, com aplicação da questão geradora de debate (QGD) "Eu sou... estou ... quero... ". Para a realização dessa dinâmica, foram utilizados rádio, filmadora, gravador, material de papelaria para que os adolescentes se familiarizassem com todo material que fosse ser utilizado nos encontros. Tocou-se uma música de fundo e circulou um saco, entre os adolescentes, contendo pares de balas doces e pedindo para cada um retirar uma bala. Após a distribuição aos participantes, cada um encontrou o seu par (bala igual) e foi solicitado que assentassem ao lado do par; cada um devia então apresentar seu par baseado na questão de debate. Compareceram nesse encontro 6 meninas e 3 meninos. 2o encontro - Produção do jogo educativo e, aplicado a dinâmica: "Transformando novamente...", com a QGD “Como a história em quadrinhos "Beber compensa?" pode ser transformada em jogo educativo?'. Foram distribuídos jogos de dominó, bingo e jogo de tabuleiro para que eles jogassem com o propósito de estimular a criatividade e o interesse pela jogabilidade. Após, os jogos foram recolhidos e foi aplicado a QGD. Nesse encontro eles definiram o formato e tipo de jogo, público alvo, além das regras do jogo. Após, a equipe de pesquisadores afastaram-se do campo para analisar, discutir e produzir o storyboard provisório com o jogo escolhido pelos adolescentes e baseado em suas narrativas.

$3^{\circ}$ encontro - 3 ${ }^{\underline{a}}$ dinâmica: com o objetivo de avaliar o storyboard produzido em relação ao conteúdo informativo, operacionalização e as regras do jogo, foi aplicado a dinâmica "Encurtando distâncias entre o que se produziu e o jogo educativo" com aplicação da QGD "As informações são... as regras estão... o jogo é..." foram distribuídos os materiais de papelaria e solicitado que respondessem a QGD. Compareceram nesse encontro 5 meninas.

0 grupo definiu, planejou, organizou e montou o jogo tendo como base o almanaque produzido e avaliado na comunidade Quilombola onde residem. Ocorreram 3 encontros, com duração mínima de 30 e máximo de 1 hora e 25 minutos.

A pesquisa que deu origem a esse relato de experiência foi aprovada com parecer número 2.414.916 pelo CEP do Centro Universitário Norte do Espírito Santo/Universidade Federal do Espírito Santo. Os adolescentes tiveram direito ao anonimato, ou seja, o nome do adolescente não foi exposto, sendo identificados pela sigla AD seguido do sexo e ordem (ADM1, ADF4...).

Para composição dos resultados deste relato de experiência, as informações foram extraídas do relatório de campo onde eram descritas as atividades diárias dos encontros, das análises do conteúdo do relatório e do processo de confecção do jogo. 


\section{RESULTADOS}

Participaram nove adolescentes com idades entre 11 e 15 anos. Oito eram católicos, um evangélico e todos eram solteiros. Três estudavam na escola pluridocente da comunidade (pré ao $5^{\circ}$ ano do ensino fundamental) e seis na Escola Família Agrícola (6oa ano do ensino fundamental ao ensino médio). Os nove residiam em casa própria e possuíam renda familiar mensal abaixo de um salário mínimo.

Inicialmente, os adolescentes ficaram na dúvida sobre o tipo de jogo que melhor se aplicaria à transformação da HQ “Beber compensa?”. Sugeriram o bingo, dominó e memória como jogos em potencial para essa transformação:

A história pode virar um bingo. Ao invés de números, as cartelas podem ter imagens e cartas com informações da história. (...) ia fica legal como bingo. (ADF1)

(...) Pode ser transformado em um jogo de dominó, porque tem imagem e informação que podem ser combinadas. (ADM1)

(...) melhor um jogo de memória. (ADM2)

Poderia colocar as imagens da história nas peças. (ADF4)

Também discutiram sobre o tipo de jogo que não atenderia a transformação da História em Jogo:

(...) não dá para virar um jogo de cartas. (ADF2)

Como não houve consenso na definição do tipo de jogo, na dinâmica grupal se sugeriu que houvesse votação. Assim, pela maioria o grupo decidiu pelo jogo tipo Bingo. Houve consenso em relação a classificação etária para pessoas acima de 10 anos, com no máximo seis jogadores, composto por seis cartelas com imagens orientadoras/equivalentes para as 27 cartas, um dado com numeração e marcadores (botões, pedrinhas, grãos etc, ou qualquer objeto que possa servir de marcador).

Após essas definições, as informações foram unificadas, analisadas pela equipe de pesquisadores e elaborado um storyboard provisório (Figura 1). As cartelas do bingo e as cartas com informações textuais e imagéticas foram extraídos da Seção 'Você Sabia' do almanaque 'Álcool e ritos de adolescentes em uma comunidade Quilombola'. As informações das cartas foram associadas a uma imagem da cartela (Figura 1). Os pesquisadores sintetizaram as regras do jogo que foi compartilhado pelo grupo de adolescentes no espaço de discussão grupal.

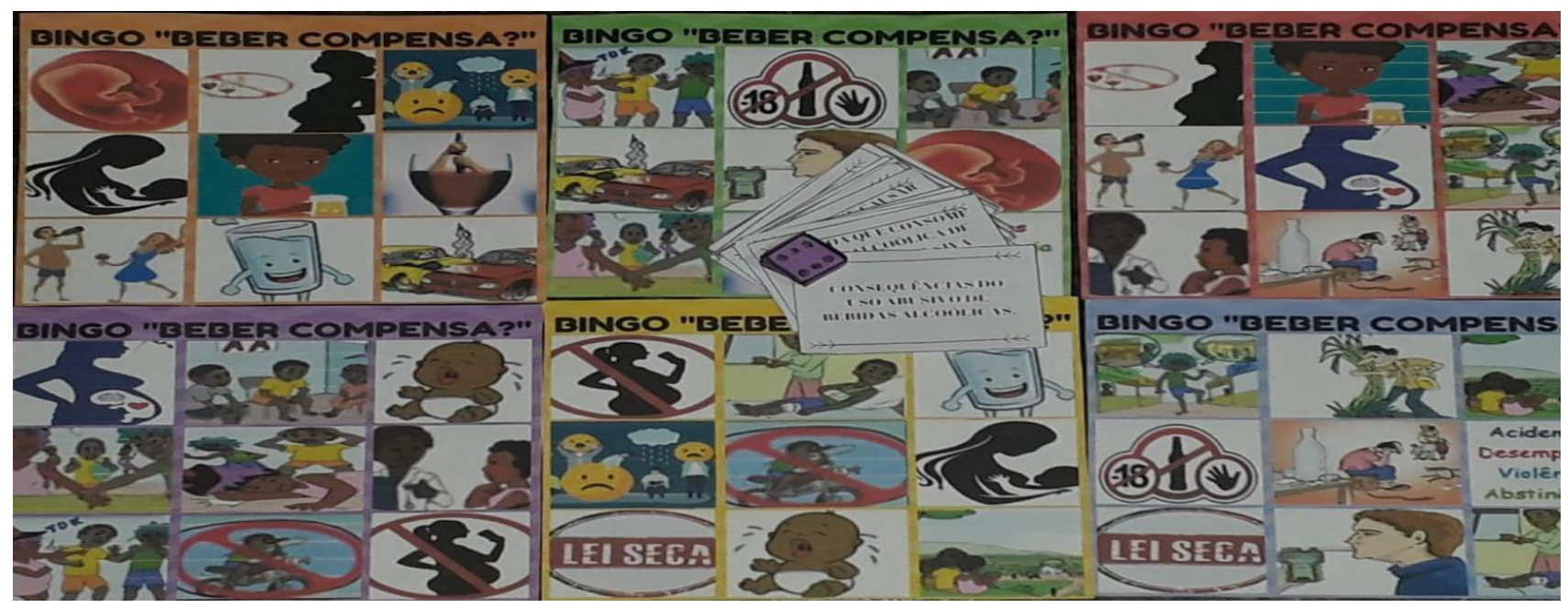

Figura 1. Storyboard provisório do Bingo “Beber Compensa”. Espírito Santo, 2019.

0 grupo de pesquisadores retornou à comunidade para avaliar o jogo de bingo (storyboard provisório) com os adolescentes aplicando-se a dinâmica "Encurtando distâncias entre o que se produziu e o jogo educativo" com aplicação da QGD "As informações são... as regras estão... o jogo é...".

As narrativas do grupo revelaram que as imagens da cartela do bingo precisavam ser modificadas para expressar melhor a lógica do jogo: 
O jogo é legal, mas tem que mudar algumas imagens! Essa imagem do AA (informações sobre os alcoólicos anônimos) tem que ser maior ... (ADF1)

(...) deve ter imagem que mostre a dependência dele, como exemplo, um homem com olhos arregalados e várias garrafas de bebidas. Essa imagem do alcoolismo tem que ter mais informação... (ADF1, ADM1 e ADM2)

A imagem do homem bêbado abraçado a um pé de cana de açúcar deve ser mudada. (ADF4).

O conteúdo escrito nas cartas também deveria ser alterado para melhor compreender o significado da informação que estava sendo mediada:

É! Tá difícil ... Eu não conheço essa palavra ('coordenação motora'), aqui na comunidade fala "cambaleando", é isso?! (ADF1)

Sim, tem palavras difíceis! (ADF2)

Tem que ser mais fácil a informação da cartinha. Coloca palavras que a gente conhece. (ADM2)

Foi a lei seca! Acho melhor colocar: lei que não permite nenhuma quantidade de álcool no sangue do condutor. (ADF3)

Em relação às regras do jogo, o grupo fez algumas ponderações:

Acho que tem que mudar o começo. Jogar o dado para saber quem é primeiro e a sequência de jogadores é ruim ... (ADF3) (ADF1)

Sim, a gente esquece quem vai ser o próximo a jogar. (ADF3)

Então, para saber quem será o primeiro a jogar tirar a sorte nos dados. Começa o jogador que tirar o maior número seguindo a sequência dos jogadores que estão (posicionados) à direita (daquele que começou jogando) ... (ADF3)

$\mathrm{Na}$ avaliação final, os adolescentes aprovaram e gostaram do jogo educativo proposto:

Gostei, só falta mudar um pouco! (ADF1)

Só mudar mesmo o que falamos! (ADM1)

Desta forma, o grupo de pesquisadores se reuniram e analisaram as sugestões dos adolescentes, e remodelou o jogo para Jogo de Imagens, onde foram mantidas as seis cartelas com imagens orientadoras/equivalentes para as 27 cartas, um dado com numeração e marcadores (botões, pedrinhas, grãos, ou qualquer objeto que possa servir de marcador). 0 material remodelado foi entregue ao ilustrador produzindo a versão final do jogo (Figura 2).
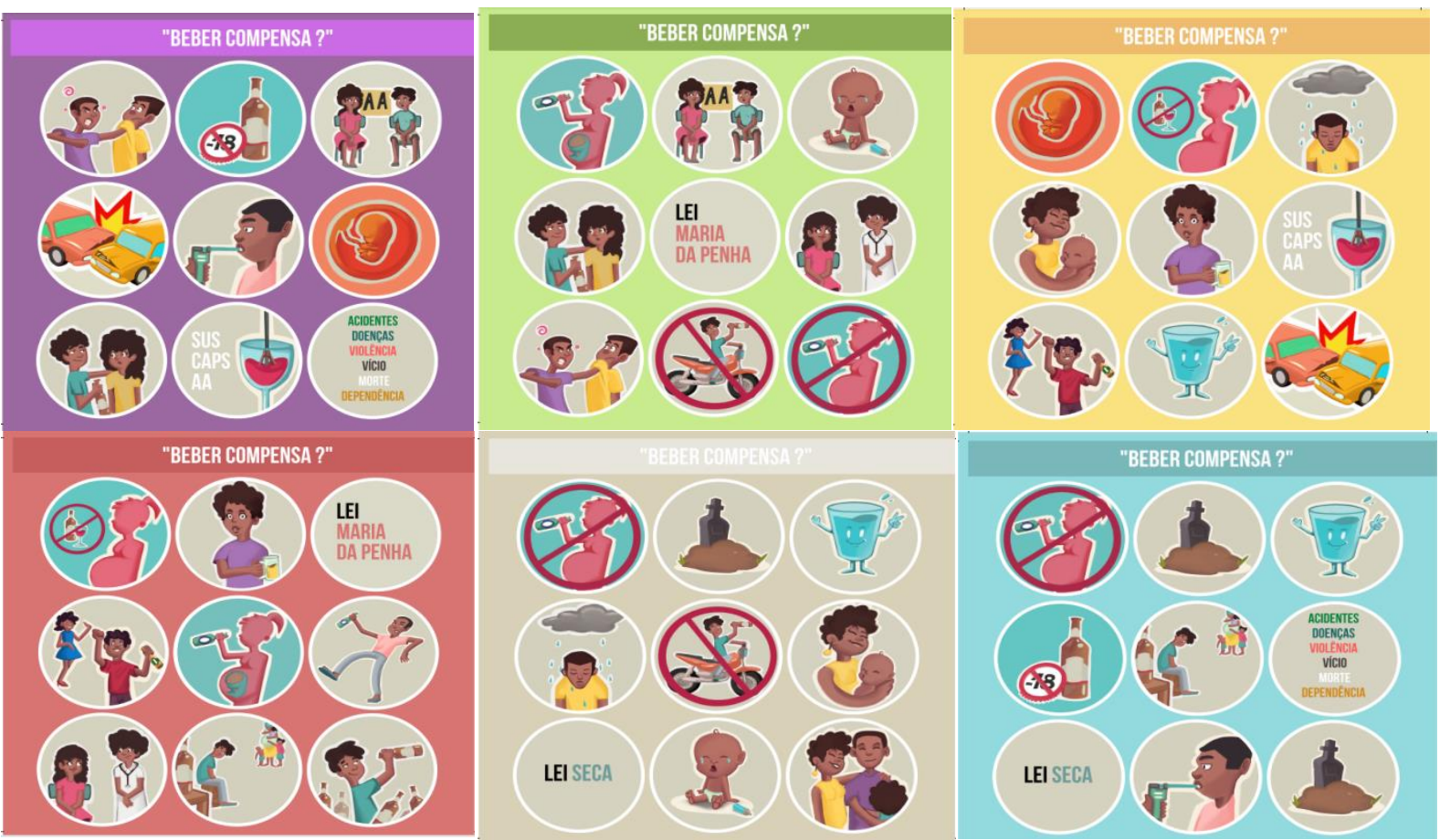

Figura 2. Cartelas do Jogo de Imagens "Beber Compensa”, alterado do jogo de Bingo. Espírito Santo, 2019. 
As cartas contém informações e ao abri-las, é revelado a imagem correspondente na cartela (Figura 3).
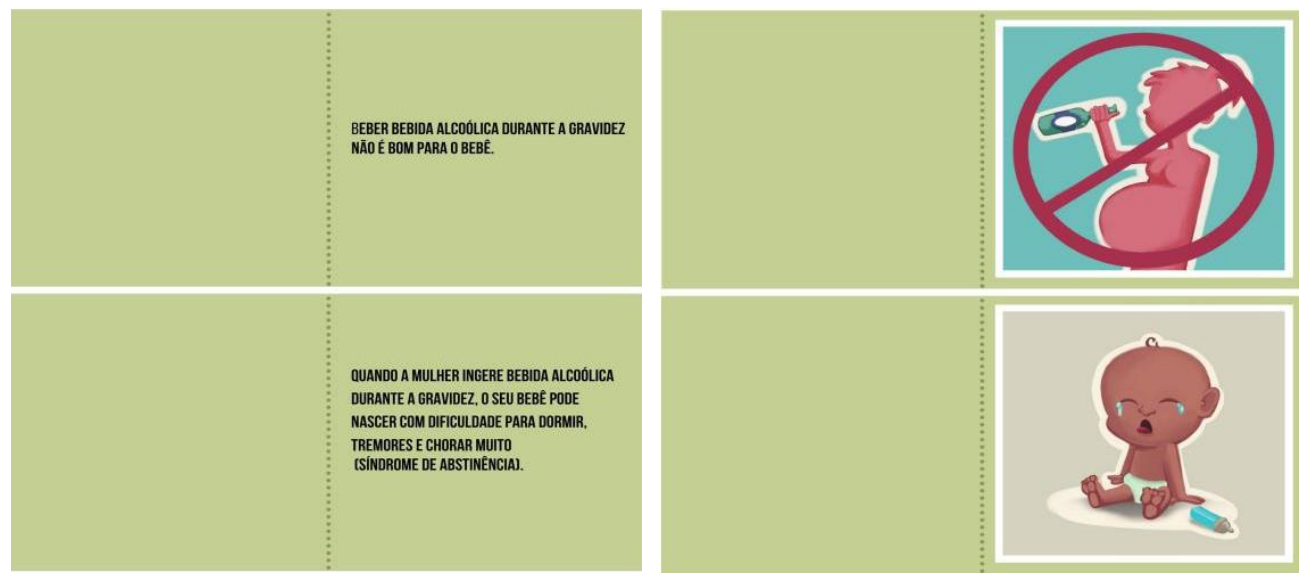

Figura 3. Recorte de cartas e imagens do Jogo de Imagens. Espírito Santo, 2019.

As regras do jogo também foram alteradas, conforme sugestões dos adolescentes (Quadro 1).

Quadro 1. Regras do Jogo de Imagens. Espírito Santo, 2019.

\begin{tabular}{|c|c|}
\hline \multicolumn{2}{|c|}{ Regras do Jogo de Imagens } \\
\hline Preparação & Comece o jogo \\
\hline $\begin{array}{l}\text { 1. Número de jogadores até 6; } \\
\text { 2. Escolher grãos, botões, etc para marcar as } \\
\text { cartelas; } \\
\text { 3. Embaralhe as cartas e coloque-as com a } \\
\text { parte escrita para baixo em um monte; } \\
\text { 4. Escolha uma das } 6 \text { cartelas; } \\
\text { 5. Escolher uma ou mais modalidades para } \\
\text { ganhar/finalizar o jogo. } \\
\text { Sugestões: } \\
\text { Quina ( } \square \text { ), janela ( } \\
\text { L ( } \leftarrow \text { ) ou cartela cheia ( })\end{array}$ & $\begin{array}{l}\text { 1. Para saber quem será o primeiro a jogar, os participantes } \\
\text { devem tirar a sorte nos dados. O jogador que tirar o maior } \\
\text { número no dado começa a jogar, seguindo a ordem } \\
\text { decrescente para os demais jogadores; } \\
\text { 2. Cada jogador, na sua vez, pega uma carta do monte e lê em } \\
\text { voz alta para os demais jogadores que deverão marcar a } \\
\text { imagem correspondente à informação escrita, se estiver na } \\
\text { sua cartela; } \\
\text { 3. O jogador que leu a carta revelará a imagem } \\
\text { correspondente contida na } 2^{\text {a }} \text { parte da carta a todos os } \\
\text { jogadores. Permanecem com a cartela marcada aqueles que } \\
\text { tiveram a imagem idêntica a revelada; } \\
\text { 4. A carta retirada do monte deverá ser descartada da } \\
\text { partida. }\end{array}$ \\
\hline \multicolumn{2}{|r|}{ Final do jogo } \\
\hline & \\
\hline
\end{tabular}

\section{DISCUSSÃO}

Esse relato retratou a produção, com a participação de adolescentes residentes em comunidade Quilombola e pesquisadores, do jogo de imagens "Beber Compensa" com a temática álcool, utilizando uma HQ do almanaque "Álcool e ritos de adolescentes em uma comunidade Quilombola". Essa construção ocorreu no meio de convivência social, numa relação criativa e de respeito ao vocabulário usado no cotidiano dos adolescentes.

A pesquisa metodológica participativa e conduzida segundo a perspectiva freiriana de diálogo e leitura de mundo ${ }^{5}$ permitiu a construção do jogo de imagem sobre o uso social do álcool. As experiências de adolescentes que vivem em uma comunidade Quilombola, seus costumes e saberes locais foram a matéria prima da HQ que foi transformado em jogo.

No espaço das DCS, adolescentes e pesquisador compreenderam as "razões de ser" e de "ler" o mundo de cada um que fez parte do grupo, pois o ser humano é histórico; quanto mais se reflete sobre o seu viver, mais se torna crítico e produz conhecimento. A Política Nacional da Saúde Integral da População Negra, tem entre os pressupostos a garantia de atenção integral à 
população negra, enfatizando a vida saudável e ativa e fortalecendo o protagonismo das pessoas negras no processo de transformação da realidade ${ }^{5,8}$. Trata-se de uma outra cultura, que exigiu um íntimo respeito e diálogo diante das especificidades do contexto histórico e sociocultural de sua realidade local que foram incorporadas no jogo, com potencial para uso nas abordagens de promoção da saúde na comunidade e na escola.

O consumo precoce de álcool na adolescência está associado a problemas comportamentais e sociais, além do risco de se tornar um adulto dependente da substância ${ }^{9}$. As primeiras experiências com álcool para muitos ocorrem no contexto familiar com supervisão dos pais ${ }^{10}$, podendo torna-se um consumo excessivo quando associadas a cor negra ou parda, a não ter uma religião, escolaridade menor que oito anos, composição familiar mononuclear e ter um trabalho ${ }^{2}$. Desta forma, os adolescentes trazem consigo diversos saberes que são adquiridos pela experiência no meio onde vivem, valorizando a bebida alcoólica como elemento imprescindível no momento de lazer, na aproximação com o sexo oposto, além da sensação de prazer e liberdade e necessidade de afirmação no universo adulto ${ }^{11}$.

No Reino Unido se recomenda uma infância sem álcool e que os jovens que optem por consumi-lo não devem fazê-lo antes de 15 anos e, se beberem, não deve exceder as recomendações de adultos e não deve beber mais de uma ocasião por semana ${ }^{9}$. No Brasil, a lei é mais restrita, proibindo o uso e a comercialização do álcool na adolescência e criminalizando a pessoa que vende, fornece, serve, ministra ou entrega bebida alcoólica à criança ou ao adolescente $^{12}$. Desta forma, as tecnologias educacionais, como os jogos educativos, são importantes mediadores para a promoção da saúde.

0 jogo proporciona a memorização da informação pelo estímulo ao entusiasmo do aprendiz e por seu maior envolvimento, podendo ser usado nos diversos momentos do processo de ensino e aprendizagem. Jogo é um termo do latim "jocus", que significa brincadeira, divertimento. É uma atividade física ou intelectual que integra um sistema de regras e define um indivíduo (ou um grupo) vencedor e outro perdedor ${ }^{13}$.

Em estudo sobre uso de jogos na promoção da saúde de adolescentes, observou-se que a maioria dos jogos são online onde os adolescentes necessitam de computadores e conexão à internet, beneficiando uma parcela da sociedade, geralmente da área urbana, de classe econômica média a alta, ficando de fora adolescentes residentes em área rural que não possuem acesso à internet ou esse acesso é restrito, e de baixa classe econômica social ${ }^{14}$. Desta forma, a produção de jogos manuais que envolvem aspectos subjetivos dos participantes relativos a ideias, opiniões, crenças, preconceitos, mitos ${ }^{14}$, deve ser estimulado para ser utilizado pelos profissionais de saúde para a promoção a saúde.

Desde o final do século XX, cada vez mais estudos tem demonstrado o uso de tecnologias educacionais para o cuidado da vida e saúde de pessoas, grupos e comunidades, pois a tecnologia apresenta potencial poder de educar e trazer a consciência do empoderamento do cuidar15-17.

Tais reflexões convergem com a experiência aqui relatada. A educação dialógica freiriana ${ }^{5}$ no contexto da saúde e do fazer da enfermagem enunciam um paradigma próprio de pensar e educar, colocando a dimensão subjetiva dos educandos como parte do processo de construção e avaliar o jogo educativo, centrado no diálogo, na decodificação dos temas, na compreensão dos significados para a produção do jogo educativo. A educação dialógica em saúde é um caminho alternativo de atuação da enfermeira junto aos educandos ${ }^{17}$.

Neste relato de experiência, apresentou-se momentos de interação e reflexão com o público a quem se destina o material educativo produzido, na expectativa de desenvolver interesse e sentido no cuidado de sua própria saúde e do grupo que fazem parte. 


\section{CONCLUSÃo}

A construção do jogo educativo unindo saberes locais dos adolescentes e saberes científicos sobre o álcool, proporcionou uma aproximação significativa e positiva levando a discussão e a reflexão sobre tema que interferem em sua condição de saúde, por uma abordagem que ultrapassa a visão biomédica.

Dessa forma, unindo os saberes da cultura local com saberes científicos para construção de jogos educativos na área da saúde, é um recurso que facilita a discussão de temas relevantes para a saúde individual e coletiva.

0 objetivo deste estudo foi alcançado com o emprego do MCS, que favoreceu a expressão da crítica reflexiva do adolescente de comunidade Quilombola que se diferencia dos jovens inseridos em outros contextos, culturas e classes sociais, pois, as formas como eles vivenciam o processo de adolescer são influenciadas por princípios conservadores e tradicionais, em função da reprodução de valores e comportamentos vivenciados no contexto familiar que são constantemente reforçados pela comunidade.

Como limitações, destaca-se que o estudo foi desenvolvido em uma comunidade Quilombola impossibilitando a generalização dos dados e o critério de inclusão dos participantes que foram estudantes. 0 perfil de participantes incluídos não atingiu a população de adolescentes fora do espaço escolar, que pode estar relacionado ao aumento da vulnerabilidade e maior exposição ao consumo de álcool.

Compreendeu-se que o resultado deste estudo pode impactar na orientação não só de adolescentes Quilombolas, mas também outros adolescentes que estejam nessa fase tão estigmatizada pela sociedade, por pais e educadores.

\section{REFERÊNCIAS}

1. Instituto Brasileiro de Geografia e Estatística. Pesquisa Nacional de Saúde do Escolar [Internet]. Rio de Janeiro: IBGE; 2016 [citado em 05 set 2018]. Disponível em: https://biblioteca.ibge.gov.br/visualizacao/livros/liv97870.pdf

2. Guimarães BEB, Aquino R, Prado NMBL, Rodrigues PVA. O consumo excessivo de álcool e a insatisfação com a imagem corporal por adolescentes e jovens de um município baiano, Brasil. Cad Saúde Pública [Internet]. 2019 [citado em 28 jun 2020]; 36(1):1-15. Disponível em: https://www.scielo.br/pdf/csp/v36n1/1678-4464-csp-36-01-e00044919.pdf

3. Silveira RE, Santos AS, Albino A. Identidade de gênero entre adolescentes escolares: abordagens sociais e psicanalíticas. REFACS [Internet]. 2016 [citado em 14 abr 2020]; 4(3):227-36. Disponível em: http://seer.uftm.edu.br/revistaeletronica/index.php/refacs/article/view/1775/1730. DOI: 10.18554/refacs.v4i3.1775

4. Couto TA, Santos FPA, Rodrigues VP, Vilela ABA, Machado JC, Jesus AS. Health education under perspective of family health teams users. Rev Enferm UFPE [Internet]. 2016 [citado em 03 mar 2019]; 10(5):1606-18. Disponível em: https://periodicos.ufpe.br/revistas/revistaenfermagem/article/view/11156/0

5. Freire P. Pedagogia do oprimido. 55ed. Rio de Janeiro: Paz e Terra; 2013.

6. Partelli ANM, Cabral IE. Stories about alcohol drinking in a Quilombola community: participatory methodology for creating-validating a comic book by adolescents. Texto \& Contexto Enferm. [Internet]. 2017 [citado em 22 mar 2019]; 26(4):e2820017. DOI: https://doi.org/10.1590/010407072017002820017

7. Cabral IE, Neves ET. Pesquisar com o método criativo e sensível na enfermagem: fundamentos teóricos e aplicabilidade. In: Lacerda RM, Costenaro RGS, organizadores. Metodologia da pesquisa para a enfermagem: da teoria à prática. Porto Alegre: Moriá; 2016. p. 325-351.

8. Ministério da Saúde (Br). Política Nacional de Saúde Integral da População Negra: uma política para o SUS [Internet]. 2ed. Brasília, DF: Editora MS; 2013 [citado em 03 jul 2020]. Disponível em: http://bvsms.saude.gov.br/bvs/publicacoes/politica_nacional_saude_integral_populacao.pdf

9. Donoghue K, Rose H, Boniface S, Deluca P, Coulton S, Mohammed FA, et al. Alcohol consumption, early-onset drinking, and health-related consequences in adolescents presenting at emergency 
departments in England. J Adolesc Health [Internet]. 2017 [citado em 02 abr 2020]; 60(4):438-46. DOI: https://doi.org/10.1016/j.jadohealth.2016.11.017

10. Colder CR, Shyhalla K, Frndak SE. Early alcohol use with parental permission: psychosocial characteristics and drinking in late adolescence. Addict Behav. [Internet]. 2018 [citado em 28 jun 2020]; 76:82-7. DOI: http://dx.doi.org/10.1016/j.addbeh.2017.07.030

11. Freitas EAM, Luis MAV. Perception of students about alcohol consumption and illicit drugs. Acta Paul Enferm. [Internet]. 2015 [citado em 28 jun 2020]; 28(5):408-14. Disponível em: https://www.scielo.br/pdf/ape/v28n5/en_1982-0194-ape-28-05-0408.pdf

12. Presidência da República (Brasil), Casa Civil. Lei n. 8.069, de 13 de julho de 1990. Dispõe sobre o Estatuto da Criança e do Adolescente e dá outras providências [Internet]. D.O.U., Brasília, DF, 16 jul 1990 [citado em 03 jul 2020]. Disponível em: http://www.planalto.gov.br/ccivil_03/leis/18069.htm

13. Gurgel SS, Taveira GP, Matias ÉO, Pinheiro PNC, Vieira NFC, Lima FET. Jogos educativos: recursos didáticos utilizados na monitoria de educação em saúde. REME Rev Min Enferm. [Internet]. 2017 [citado em 05 maio 2020]; 21:e-1016. Disponível em: http://www.reme.org.br/artigo/detalhes/1152

14. Yonekura T, Soares CB. 0 jogo educativo como estratégia de sensibilização para coleta de dados com adolescentes. Revista Latinoam Enferm. [Internet]. 2010 [citado em 05 jun 2019]; 18(5):1-7. Disponível em: https://www.scielo.br/pdf/rlae/v18n5/pt_18.pdf

15. Arevian AC, O'Hora J, Jones F, Mango J, Jones L, Williams PG, et al. Participatory technology development to enhance community resilience. Ethn Dis. [Internet]. 2018 [citado em 05 jan 2020]; 28(Suppl 2):493-502. Disponível em: https://www.ncbi.nlm.nih.gov/pmc/articles/PMC6128332/pdf/ethndis-28-493.pdf

16. West CH, Dusome DL, Winsor J, Rallison LB. Falling down the rabbit hole: child and family experiences of pediatric hematopoietic stem cell transplant. Qual Health Res. [Internet]. 2020 [citado em 05 jan 2020]; 30(7):1125-38. DOI: https://doi.org/10.1177/1049732320912410

17. Teixeira E, organizadora. Desenvolvimento de tecnologias cuidativo-educacionais. Porto Alegre: Moriá; 2017.

\section{CONTRIBUIÇõES}

Adriana Nunes Moraes-Partelli participou da concepção, coleta e análise dos dados, redação e revisão. Aline Pestana Santos e Séfora Gasparini Santos colaboraram na coleta, análise dos dados e redação. Marta Pereira Coelho contribuiu na coleta e análise dos dados, redação e revisão.

\section{Como citar este artigo (Vancouver)}

Moraes-Partelli AN, Santos AP, Santos SG, Coelho MP. Produção compartilhada de jogo educativo sobre álcool com adolescentes de comunidade Quilombola. REFACS [Internet]. 2020 [citado em inserir dia, mês e ano de acesso]; 8(Supl. 2):792-800. Disponível em: inserir link de acesso. DOI: inserir link do DOI.

\section{Como citar este artigo (ABNT)}

MORAES-PARTElli, A. N. M.; SANTOS, A. P.; SANTOS, S. G.; COELHO, M. P. Produção compartilhada de jogo educativo sobre álcool com adolescentes de comunidade Quilombola. REFACS, Uberaba, MG, v. 8, p. 792-800, 2020. Supl. 2. Disponível em: inserir link de acesso. Acesso em: inserir dia, mês e ano de acesso. DOI: inserir link do DOI.

\section{Como citar este artigo (APA)}

Moraes-Partelli, A.N.M., Santos, A.P.; Santos, S.G. \& Coelho, M.P. (2020). Produção compartilhada de jogo educativo sobre álcool com adolescentes de comunidade Quilombola. REFACS, 8(Supl. 2), 792-800. Recuperado em inserir dia, mês e ano de acesso de inserir link de acesso. DOI: inserir link do DOI. 